\title{
Molecular Dynamics Simulation of Reinforcing Steel Corrosion when Subjected to Both Chloride Attack and Mechanical Loading
}

\author{
Yidong XU ${ }^{1}$, Jianke FANG ${ }^{1,2}$, Jiansheng SHEN ${ }^{1}$, Wei CHEN ${ }^{1}$, Ruoyu JIN ${ }^{3}$, \\ Yingying ZHENG ${ }^{1,2}$, Jianghong MAO ${ }^{1}$, Weiliang JIN ${ }^{1,4}$
}

\author{
${ }^{1}$ Ningbo Institute of Technology, Zhejiang University, Ningbo, 315100, China \\ ${ }^{2}$ School of Civil Engineering, Chongqing Jiaotong University, Chongqing, 400074, China \\ ${ }^{3}$ School of Environment and Technology, University of Brighton, Brighton, BN2 4GJ, UK \\ ${ }^{4}$ Institute of Structural Engineering, Zhejiang University, Hangzhou, 310058, China
}

crossref http://dx.doi.org/10.5755/j01.ms.26.3.20896

Received 05 June 201X; accepted 27 January 2019

\begin{abstract}
This paper describes the corrosion process of reinforcing steel under both chloride attack and mechanical loading. Molecular dynamics simulation is adopted to investigate the evolution process of passive film and oxidation process of reinforcement. The mean square displacement and self-diffusion coefficient of $\mathrm{O}_{2}$ under different conditions are also obtained based on molecular dynamics simulation. It is shown that the present of chlorides can increase the energy of $\mathrm{Fe}$ atoms on the surface of $\mathrm{Fe}_{3} \mathrm{O}_{4}$ substrate, leading $\mathrm{Fe}$ atoms to separate from $\mathrm{Fe}_{3} \mathrm{O}_{4}$ easily and to get more chance to react with oxygen atoms. The interaction of chloride attack and mechanical loading can aggravate the damage of passive film on the surface of reinforcement and result in an increase of oxidation depth of Fe matrix. The coupled effects of chloride and static loading can accelerate the diffusion of $\mathrm{O}_{2}$ to the iron matrix, thus increasing the oxidation reaction between the iron matrix and $\mathrm{O}_{2}$.

Keywords: chloride attack, mechanical loading, reinforcement corrosion, molecular dynamics, passive film, oxidation process.
\end{abstract}

\section{INTRODUCTION}

The corrosion of reinforcing steel in concrete is one of the major causes of durability problems for reinforced concrete structures [1,2]. It affects a large number of infrastructures, particularly those that are exposed to marine environments. In order to promote the effective application of reinforced concrete and ensure that the structure made from it has good performance during its service life, it is necessary to understand the mechanisms that how the reinforcement corrodes in a given environment condition and how its deterioration affects the performance of the structure.

Considerable research work has been carried out on the corrosion mechanism of reinforcement. Ji et al. described the process control of reinforcement corrosion in concrete and investigated the coupled effects of oxygen and corrosion products on the corrosion process of reinforcement in concrete structures [3,4]. Stefanoni et al. measured local corrosion potentials, and the cathodic and anodic polarization curves on the reinforcement with different surface conditions by using "ec-pen" sensors [5]. Based on long-term durability tests, Sistonen et al. proposed three probable corrosion mechanisms of hot-dip galvanised reinforcement bar in cracked concrete [6]. Chitty et al. presented an analytical study on the long-term corrosion properties of ferrous reinforcement embedded in binders found in ancient buildings and investigated the morphological and physicochemical properties of corrosion products by using various modern methods of materials testing such as optical and electronical microscopies, energy dispersive spectrometry coupled with scanning electron microscopy, mercury porosimetry, micro-Raman spectroscopy and micro-diffraction under synchrotron radiation [7].

Many researchers have investigated the influence of coupled chemo-mechanical process on the corrosion characteristics of reinforcement [2, 8]. Jaffer and Hansson investigated the composition and distribution of chlorideinduced corrosion products of reinforcement in crackedconcrete with different loading conditions [9]. François and Ballim conducted the experiment on reinforced concrete elements under simultaneous loading and corrosion conditions $[10,11]$. Their results showed that the load applied to a reinforced concrete beam plays an important role in the corrosion evolution of the reinforcement. Yu et al. discussed the corrosion initiation and propagation in precracked reinforced concrete beams under a sustained loading condition while the beams were exposed to a chloride environment [12]. Jin et al. described the corrosivecracking behavior of reinforced concrete members under both compressive loading and corrosive-ions attack [13].

Molecular dynamics (MD) simulation is a powerful tool that provides the real-time evolution of molecular structures and has been applied in many fields [14]; examples include the hydrogen embrittlement of metal [15], the performance of corrosion inhibitors used in concrete [16, 17], the transport properties of water in cement [18], and the moisture susceptibility of asphalt [19]. In MD simulation,

\footnotetext{
* Corresponding author. Tel.: +86-574-88229132

E-mail address: sjs@nit.zju.edu.cn (J. Shen)
} 
atoms and molecules are allowed to interact for a period of time by approximations of known physics in order to explore the physicochemical properties of structures. With MD simulation, scientists are able to examine the motion of individual atoms and molecules in a way that would not be possible to get in laboratory experiments [20]. The existing studies mentioned above on the corrosion of reinforcement are mainly focused on the macro-scale analysis of corrosion characteristics of reinforcement under a combined chemomechanical process, such as the chloride attack and mechanical loading or the carbonation and mechanical loading. However, there are very limited studies in literature which were done by using the MD simulation to investigate the corrosion evolution of reinforcement under a combined chemo-mechanical attack.

The present paper is aimed to analyse the corrosion evolution of reinforcement under combined chloride attack and tensile loading in a micro-scale level. By using MD simulation, the micro molecular model of reinforcement corrosion is established. The ReaxFF reactive force field in Materials Studio software is adopted to investigate the combined chemo-mechanical effect on the damage of the passive film and oxidation process of reinforcement.

\section{MOLECULAR DYNAMICS SIMULATION THEORY AND FORCE FIELD POTENTIALS}

MD simulation is concerned with the description of the atomic and molecular interactions that govern the microscopic and macroscopic behaviors of physical systems. In MD simulation, the time dependent behavior of atomic and molecular system is calculated, giving a view of the dynamical evolution of the system. MD simulation is feasible to investigate the physicochemical properties of solutions and structures such as the interfacial phenomena and the dynamics of water molecules and ionic species in the solutions. In the most common version, the trajectories of atoms and molecules are determined numerically by solving Newton's equations of motion for a system of interacting particles, where the forces between the particles and their potential energies are calculated using interatomic potentials or force fields.

The ReaxFF reactive force field was established by Adri van Duin, which used a general relationship between bond distance and bond order and/or between bond order and bond energy, which leads to a proper dissociation of bonds to separate atoms [21]. Note that the traditional force field is not able to model chemical reactions because of the requirement of breaking and forming bonds; whereas the ReaxFF eschews the explicit bonds in favor of bond orders, which allows for continuous bond formation and/or bond breaking.

\section{MOLECULAR DYNAMICS SIMULATION OF PASSIVE FILM EVOLUTION}

The passive film of steel in concrete is formed in the alkaline environment provided by concrete pore solutions $(\mathrm{pH}>13)$. The passive film is firmly adsorbed on the surface of reinforcement, which is very dense. Once the protective film around the reinforcement is broken, the active corrosion of the reinforcing steel occurs, which causes the durability deterioration of reinforced concrete and could lead to catastrophic failure of the structure. For reinforced concrete structures exposed to marine environment the corrosion of steel is often caused due to chloride attack. In this section, the influence of different corrosion conditions on passive film evolution is to be investigated by using MD simulation, which can illustrate the failure mechanism of passive film on the reinforcement when subjected to combined chemo-mechanical attack in a micro-scale level. Three different corrosion conditions are to be considered herein. One is the reinforcement in a wet environment; one is the reinforcement in a wet environment with chloride attack; and one is the reinforcement in a wet environment not only with chloride attack but also with a mechanically tensile load.

\subsection{Simulation details}

\subsubsection{Molecular modeling of $\mathrm{Fe}_{3} \mathrm{O}_{4}$}

The passive film around the reinforcement is mainly composed of $\mathrm{FeO}, \alpha-\mathrm{Fe}_{2} \mathrm{O}_{3}$ and $\mathrm{Fe}_{3} \mathrm{O}_{4}$. The activation energies for the oxidation and reduction reactions between any two of the three oxides are relatively small. Therefore, these compounds can interchange generally with the $\mathrm{pH}$ value in concrete pore solution [22, 23]. For a concrete structure after having a long period of service, the $\mathrm{pH}$ value of its pore solution decreases with time, in which case the main component of the passive film transforms to $\mathrm{Fe}_{3} \mathrm{O}_{4}$. Note that, $\mathrm{Fe}_{3} \mathrm{O}_{4}$ is known to be non-stoichiometric, which is likely to have defects that provides opportunity for chloride ions to penetrate into the oxide film [23]. In order to give a better description of the passive film around the reinforcement but without increasing extra computational efforts, in the present $\mathrm{MD}$ simulation the $\mathrm{Fe}_{3} \mathrm{O}_{4}$ is adopted as the passive film.

MD simulation is carried out by using Materials Studio software. A single $\mathrm{Fe}_{3} \mathrm{O}_{4}$ molecule is first constructed in the model. Then, $480 \mathrm{Fe}_{3} \mathrm{O}_{4}$ molecules are generated by using the tool "Supercell". After conducting an energy minimization for the whole molecule system, the amorphous $\mathrm{Fe}_{3} \mathrm{O}_{4}$ structure is obtained by two annealing operations. The first annealing process is conducted by considering a canonical ensemble (NVT), in which the temperature reaches $900 \mathrm{~K}$ at a heating rate of $50 \mathrm{~K} / \mathrm{ps}$. The temperature is kept at $900 \mathrm{~K}$ for $10 \mathrm{ps}$ and then decreases to $300 \mathrm{~K}$ at a cooling rate of $50 \mathrm{~K} / \mathrm{ps}$. The second annealing process is conducted by considering an isothermic-isobaric ensemble (NPT) with the same heating and cooling procedure used in the first annealing process. The molecular model of $\mathrm{Fe}_{3} \mathrm{O}_{4}$ after annealing is shown in Fig. 1.

\subsubsection{Molecular modeling of liquid water}

A $\mathrm{H}_{2} \mathrm{O}$ molecule is established by using Materials Studio software. The bond length of $\mathrm{H}-\mathrm{O}$ is $1.110 \AA$ and the bond angle of $\mathrm{H}-\mathrm{O}-\mathrm{H}$ is $109.471^{\circ}$. The $\mathrm{H}_{2} \mathrm{O}$ molecule is then optimized in a cubic box of side length $10 \AA$. After optimization, the bond length of $\mathrm{H}-\mathrm{O}$ is $0.976 \AA$ and the bond angle of $\mathrm{H}-\mathrm{O}-\mathrm{H}$ is $104.548^{\circ}$, which are nearly identical to the experimentally obtained values by Ashcroft [24]. Liquid water is simulated by considering a total of $500 \mathrm{H}_{2} \mathrm{O}$ molecules, which initially are randomly distributed in a cubic box. A water molecule system is then obtained by 
using relaxation operation, as is shown in Fig. 2. The relaxation process is conducted by considering a canonical ensemble (NVT), in which the temperature is $300 \mathrm{~K}$ and the relaxation time is $2 \mathrm{ps}$. The structure size of obtained $\mathrm{H}_{2} \mathrm{O}$ is $34.39 \AA \times 25.14 \AA \times 17.29 \AA$, the bond length of $\mathrm{H}-\mathrm{O}$ is $0.951 \AA$ and the bond angle of $\mathrm{H}-\mathrm{O}-\mathrm{H}$ is $104.292^{\circ}$.

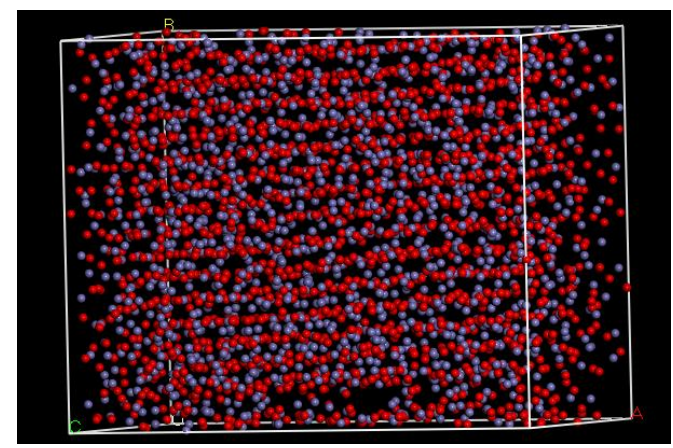

Fig. 1. Molecular modeling of $\mathrm{Fe}_{3} \mathrm{O}_{4}$ after annealing (Red balls are oxygen atoms and blue balls are iron atoms)

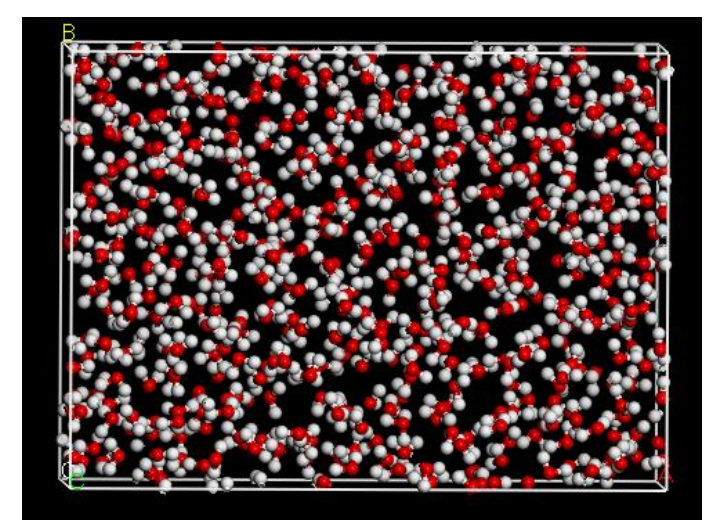

Fig. 2. Molecular modeling of $\mathrm{H}_{2} \mathrm{O}$ (Red balls are oxygen atoms and white balls are hydrogen atoms).

\subsubsection{Molecular modeling of passive film with water and chloride ions}

In the first case, the liquid water molecules (see Fig. 2) are located $2 \AA$ above the amorphous $\mathrm{Fe}_{3} \mathrm{O}_{4}$ structure (see Fig. 1), which forms a system (denoted as $\mathrm{H}_{2} \mathrm{O}+\mathrm{Fe}_{3} \mathrm{O}_{4}$ ), as is shown in Fig. 3 a. In order to investigate the influence of chloride ions on the passive film evolution, the chloride solution is simulated by further adding 10 chloride ions into the water molecule system. As mentioned above, the chloride solution is located above the amorphous $\mathrm{Fe}_{3} \mathrm{O}_{4}$ structures to form a new system (denoted as $\mathrm{Cl}^{-}+\mathrm{H}_{2} \mathrm{O}+\mathrm{Fe}_{3} \mathrm{O}_{4}$ ), as is shown in Fig. 3 b. By using a relaxation operation, the interface between water and passive film can be obtained. The relaxation process is conducted by considering a canonical ensemble (NVT), in which the temperature is $300 \mathrm{~K}$ and the relaxation time is 100 ps.

The structure size of obtained system is $34.39 \AA \times 25.14 \AA \times 66.88 \AA$, the bond length of $\mathrm{H}-\mathrm{O}$ is $0.956 \AA$ and the bond angle of $\mathrm{H}-\mathrm{O}-\mathrm{H}$ is $104.859^{\circ}$. With the application of tensile strain, the $\mathrm{H}_{2} \mathrm{O}$ molecule can interact with $\mathrm{Fe}_{3} \mathrm{O}_{4}$ at the interface and the detailed discussion can be seen in section 3.2

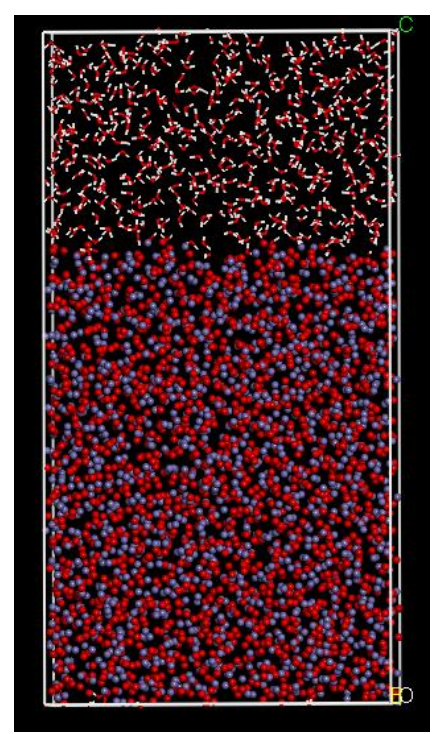

a

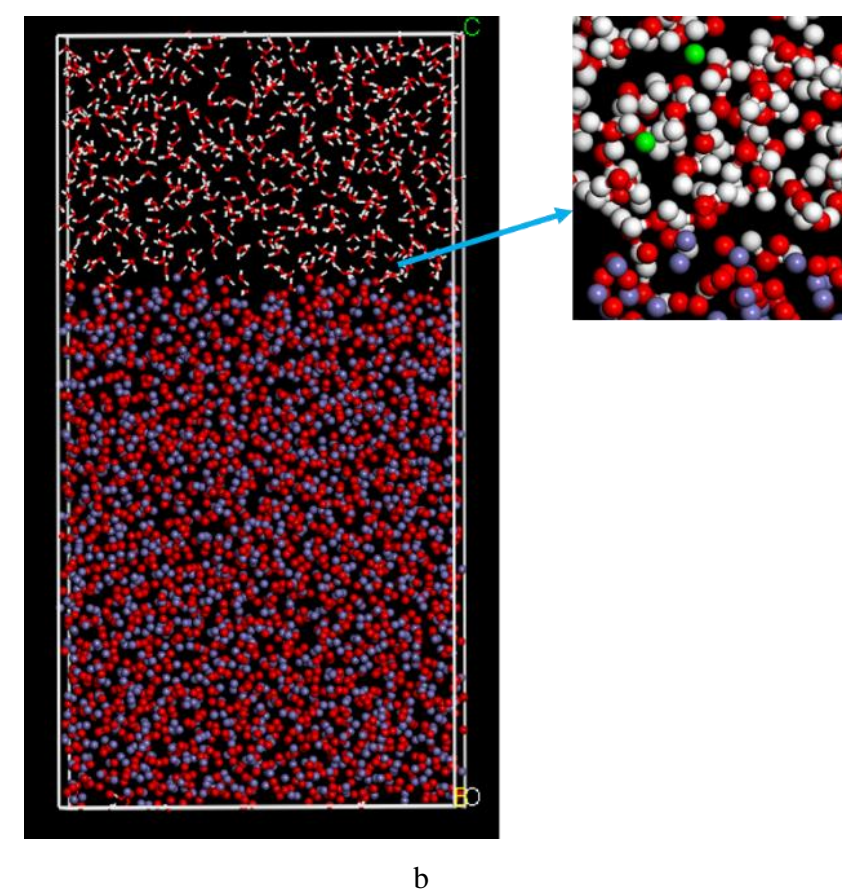

Fig. 3. Initial configurations for passive film (Green balls are chloride ions): $\mathrm{a}-\mathrm{H}_{2} \mathrm{O}+\mathrm{Fe}_{3} \mathrm{O}_{4} ; \mathrm{b}-\mathrm{Cl}^{-}+\mathrm{H}_{2} \mathrm{O}+\mathrm{Fe}_{3} \mathrm{O}_{4}$

\subsubsection{The application of uniaxial tension}

In order to investigate the passive film evolution under the action of a combined chloride attack and mechanical loading, periodic boundary conditions are applied along xaxis direction for the passive film model constructed in section 3.1.3. The model is then subjected to a uniaxial tension which is conducted in the isothermal-isobaric (NPT) ensembles with the loading rate of $0.001 / 1 \mathrm{~ns}$. The molecules on the left-hand side of the model are fixed and the strain is applied to the right-hand side of the model to obtain the deformations desired in the analysis step. The entire tension and reaction process are carried out at a constant temperature of $300 \mathrm{~K}$ and a constant pressure (one atmosphere) using the GULP code as implemented in the Materials Studio program system. Reactive force field (ReaxFF) is employed in the simulation with a time step of 
$0.5 \mathrm{fs}$. After the tension process is completed, the molecules on the both sides of the model are fixed and the system is then relaxed in a canonical ensemble (NVT) for 1 ps.

\subsection{Results and discussion}

\subsubsection{The evolution of passive film under chloride attack}

In this section, the influence of chloride ions on the structural organisation of $\mathrm{Fe}_{3} \mathrm{O}_{4}$ is investigated by using the model constructed in Fig. 3. After the completion of computation, the snapshots of molecules in the interface between $\mathrm{Fe}_{3} \mathrm{O}_{4}$ and $\mathrm{H}_{2} \mathrm{O}$ are shown in Fig. 4. It is observed from the figure that there exist significant structural differences between the two corrosion conditions. When there is no chloride ion in the system, no obvious change exists in the structure of $\mathrm{Fe}_{3} \mathrm{O}_{4}$. However, compared to the interface shown in Fig. 4 a, the transformation of $\mathrm{Fe}_{3} \mathrm{O}_{4}$ structure shown in Fig. $4 \mathrm{~b}$ is obvious. When the water contains free chloride ions, water molecules are ionized into $\mathrm{H}^{+}$and $\mathrm{OH}^{-}$. A large number of $\mathrm{Fe}$ atoms located on the top of $\mathrm{Fe}_{3} \mathrm{O}_{4}$ are combined with $\mathrm{OH}$ - in the water. The surface of $\mathrm{Fe}_{3} \mathrm{O}_{4}$ substrate becomes irregular, which indicates that the present of chloride ions in the water can damage the structure of $\mathrm{Fe}_{3} \mathrm{O}_{4}$. The results show that, the high activity of chloride ions can increase the energy of $\mathrm{Fe}$ atoms on the surface of $\mathrm{Fe}_{3} \mathrm{O}_{4}$ substrate, which makes the $\mathrm{Fe}$ atoms separate from $\mathrm{Fe}_{3} \mathrm{O}_{4}$ easily. These separated $\mathrm{Fe}$ atoms can generate $\mathrm{Fe}(\mathrm{OH})_{2}$ by further combining with $\mathrm{OH}$ - in water. After the destruction of $\mathrm{Fe}_{3} \mathrm{O}_{4}$ surface structure, chloride ions are adsorbed onto the new surface layer of $\mathrm{Fe}_{3} \mathrm{O}_{4}$, leading to new $\mathrm{Fe}$ atoms to be separated from $\mathrm{Fe}_{3} \mathrm{O}_{4}$ substrate. This process is equivalent to that the passive film on the reinforcement is gradually stripped by chloride ions until it disappears, leading to the loss of protection of reinforcement.

\subsubsection{The evolution of passive films under combined action of chloride attack and mechanical loading}

In this section, the combined effect of chloride attack and mechanical loading on the structural organization of $\mathrm{Fe}_{3} \mathrm{O}_{4}$ is investigated by using the model constructed in figure 3. As is described in section 2.1.4, the applied strain was $0.05,0.1$ and 0.2 respectively. After the completion of computation, the snapshots of molecules in the interface between $\mathrm{Fe}_{3} \mathrm{O}_{4}$ and $\mathrm{H}_{2} \mathrm{O}$ are shown in Fig. 5. It can be seen from the figure that the applied static loading affects the evolution of $\mathrm{Fe}_{3} \mathrm{O}_{4}$ structure, leading to the cracking of passive film. The crack width is found to increase with increased loading. When the applied strain is less than 0.05 , the combined effect of chloride attack and mechanical loading on the evolution of passive film is not so obvious. However, after the applied strain reaches 0.1 , cracks appear obviously in the molecular structure, as is shown in figure 5(c). When the applied strain reaches 0.2 , these cracks coalesce rapidly and the maximum crack width is about $3.566 \AA$, as is demonstrated in figure 5(d). Since some of hydrogen atoms and chloride ions can penetrate into the interior of $\mathrm{Fe}_{3} \mathrm{O}_{4}$ substrate through cracks, the bond energy between the atoms of $\mathrm{Fe}_{3} \mathrm{O}_{4}$ molecules reduces.

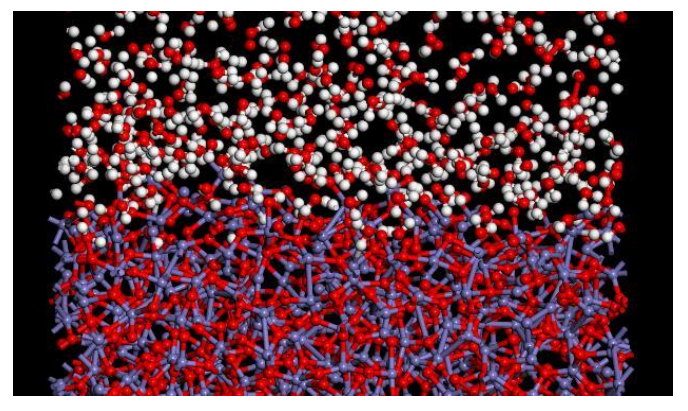

a

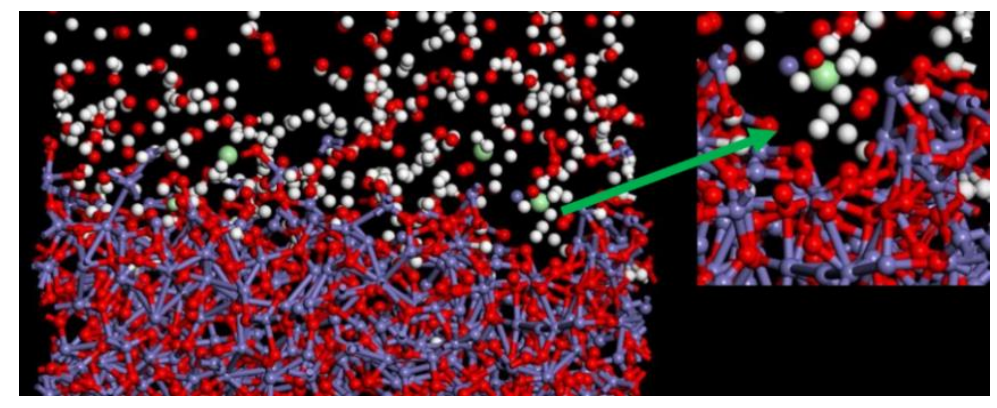

b

Fig. 4. Snapshots of molecules in the interface between $\mathrm{Fe}_{3} \mathrm{O}_{4}$ and $\mathrm{H}_{2} \mathrm{O}$ under chloride attack (Green balls are chloride ions): a-without chloride ions; $\mathrm{b}$ - with chloride ions

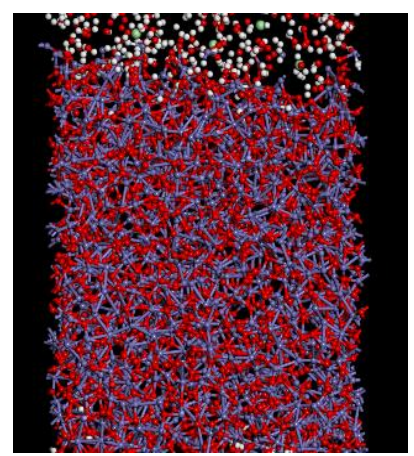

a

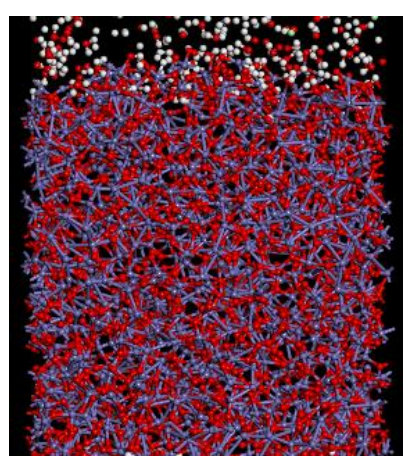

b

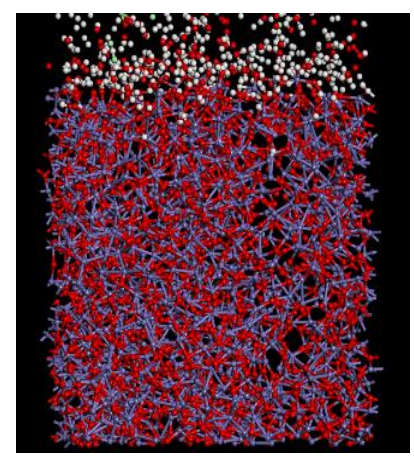

c

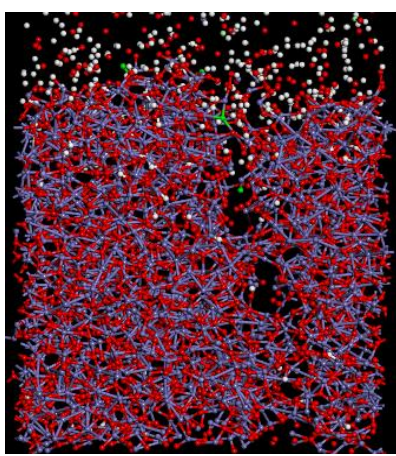

d

Fig. 5. Snapshots of molecules in the interface between $\mathrm{Fe}_{3} \mathrm{O}_{4}$ and $\mathrm{H}_{2} \mathrm{O}$ under combined action of chloride and mechanical loading (Green balls are chloride ions): $\mathrm{a}$ - without loading; $\mathrm{b}$-the applied strain is $0.05 ; \mathrm{c}$ - the applied strain is $0.1 ; \mathrm{d}$-the applied strain is 0.2 
Consequently, more hydrogen atoms can penetrate into the lower part of the $\mathrm{Fe}_{3} \mathrm{O}_{4}$ substrate, which can bond with $\mathrm{Fe}$ and $\mathrm{O}_{2}$ atoms. This is equivalent to that the passive film on the reinforcement is further stripped. When the passive film on the reinforcement is broken, the corrosive items, like water, $\mathrm{O}_{2}$ and $\mathrm{Cl}^{-}$, could contact with the iron matrix, which makes the reinforcement more vulnerable to corrosion. Thus the combined action of chloride attack and mechanical loading can accelerate the corrosion of reinforcing steel.

\section{MOLECULAR DYNAMICS SIMULATION OF OXIDATION PROCESS OFF REINFORCEMENT UNDER COMBINED CHLORIDE ATTACK AND MECHANICAL LOADING}

Note that the corrosion of iron is an oxidation-reduction process, which destroys iron object and leaves it open to moist and/or air and results in the corrosion product, called rust. This chemical process combines iron and oxygen to form iron oxide. Given sufficient time, oxygen and water, any iron mass will eventually convert entirely to rust and the original iron will become a disintegrated rust product. In this section, the oxidation process of Fe atoms is investigated by using MD simulation. The corrosion conditions used in the simulation are the same as those described in section 2 .

\subsection{Simulation details}

\subsubsection{Molecular modeling of Fe matrix}

A single Fe atom is generated by using Materials Studio software. After an optimization, the lattice constant of $\mathrm{Fe}$ is found to be about $2.857 \AA$, which is consistent to the experimental result of Kittel (2.866 ̊) [25]. After then, $1531 \mathrm{Fe}$ atoms are generated by using the tool "Supercell". The size of the constructed Fe matrix system is $28.85 \AA \times 22.86 \AA \times 22.86 \AA$. After an energy minimization of the whole system, the structure of Fe matrix system is shown in Fig. 6.

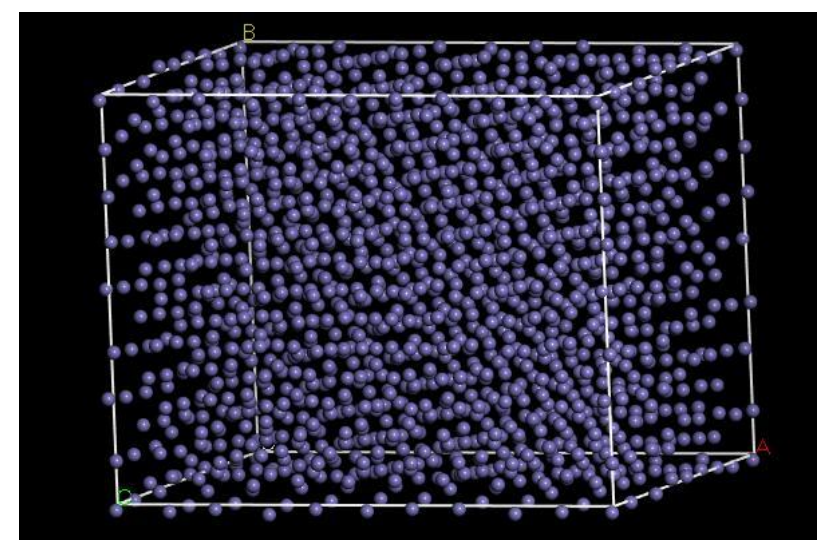

Fig. 6. Structure of Fe matrix system

In order to investigate the influence of mechanical loading on the oxidation process of reinforcement, periodic boundary conditions are applied along $\mathrm{x}$-axis direction for the Fe matrix model constructed in figure 6 . The loading and relaxation process are the same as those described in section 3.1.4. The applied strain is $0.05,0.1$ and 0.2 , respectively.

\subsubsection{Molecular modeling of $\mathrm{O}_{2}$}

Oxygen $\left(\mathrm{O}_{2}\right)$ molecule is established by using Materials Studio software, in which the bond length of $\mathrm{O}-\mathrm{O}$ is $1.840 \AA$. The $\mathrm{O}_{2}$ molecule is optimized in a cubic box of side length of $10 \AA$. The k-point set used in calculation defines the accuracy of the Brillouin zone sampling. In this study, the gamma point is chosen, which indicates that a single k-point at $(0,0,0)$ is used for the density of state calculation. After an optimization, the bond length of $\mathrm{O}-\mathrm{O}$ is found to be $1.245 \AA$, which is consistent to the experimental result of Lide (1.210 $\AA$ ) [26]. A total of 200 $\mathrm{O}_{2}$ molecules are randomly distributed in a space with the size of $28.85 \AA \times 22.86 \AA \times 136.35 \AA$. In order to obtain better simulation results but without increasing extra computational efforts, the density of oxygen is set as $0.15 \mathrm{~g} / \mathrm{cm}^{3}$, which is equivalent to the density of oxygen at ten atmospheric pressure. An $\mathrm{O}_{2}$ molecule system is then obtained by using relaxation operation, as is shown in Fig. 7. The relaxation process is conducted by considering a canonical ensemble (NVT), in which the temperature is $300 \mathrm{~K}$ and the relaxation time is $2 \mathrm{ps}$.

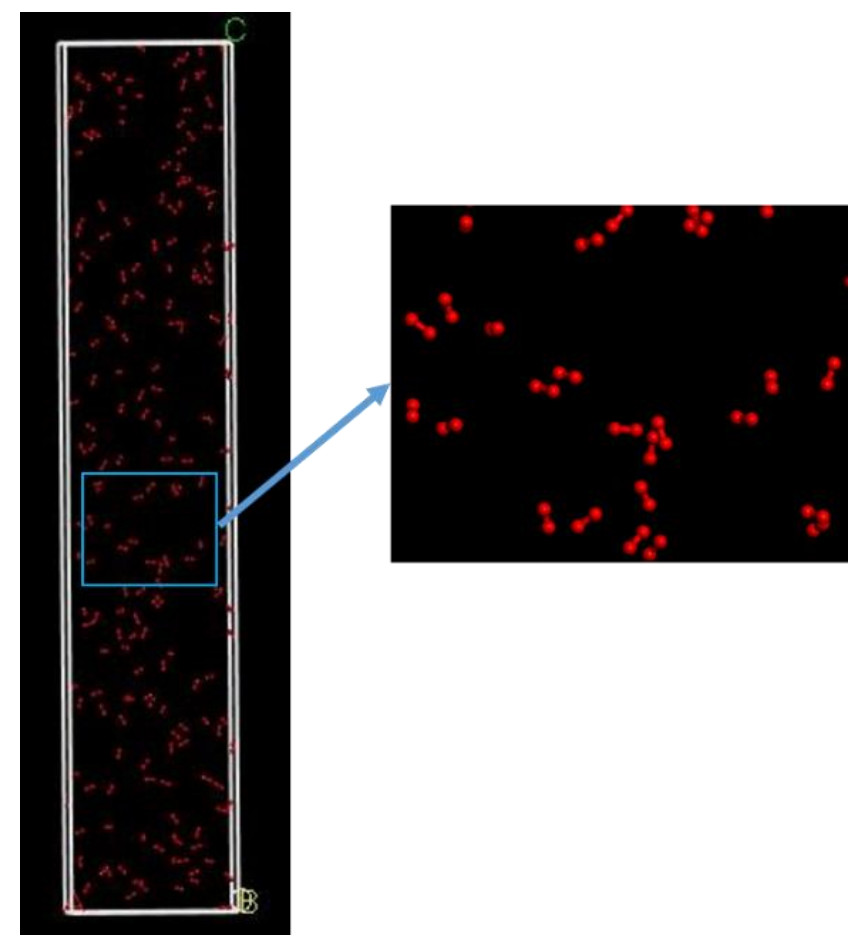

Fig. 7. Structure of $\mathrm{O}_{2}$ molecules system

\subsubsection{Molecular modeling of iron oxidation reaction}

The generated oxygen molecules (see Fig. 7) are located $2 \AA$ above the Fe matrix (see Fig. 6), which forms a system, as is shown in Fig. 8 a. In order to investigate the influence of chloride ions on the oxidation process of $\mathrm{Fe}$, ten chloride ions are added into the $\mathrm{O}_{2}$ molecule system, which is located above the Fe matrix to form a new system, as is shown in Fig. 3 b. A total of five sets of models are established, as is listed in Table 1. The five systems are relaxed to generate realistic structure models. The relaxation process is conducted by considering a canonical ensemble (NVT), in which the temperature is $300 \mathrm{~K}$ and the relaxation time is $100 \mathrm{ps}$. 
The oxidation process is conducted by using the GULP code as implemented in the Materials Studio software. The force field, time step and reaction temperature are taken to be the same as those described in section 2.1.4.

Table 1. The models employed for iron oxidation reaction

\begin{tabular}{|c|c|c|c|c|c|}
\hline Model code & L0 & L0-Cl & L5-Cl & L10-Cl & L20-Cl \\
\hline Applied strain & 0 & 0 & 0.05 & 0.1 & 0.2 \\
\hline Chloride & No & Yes & Yes & Yes & Yes \\
\hline
\end{tabular}

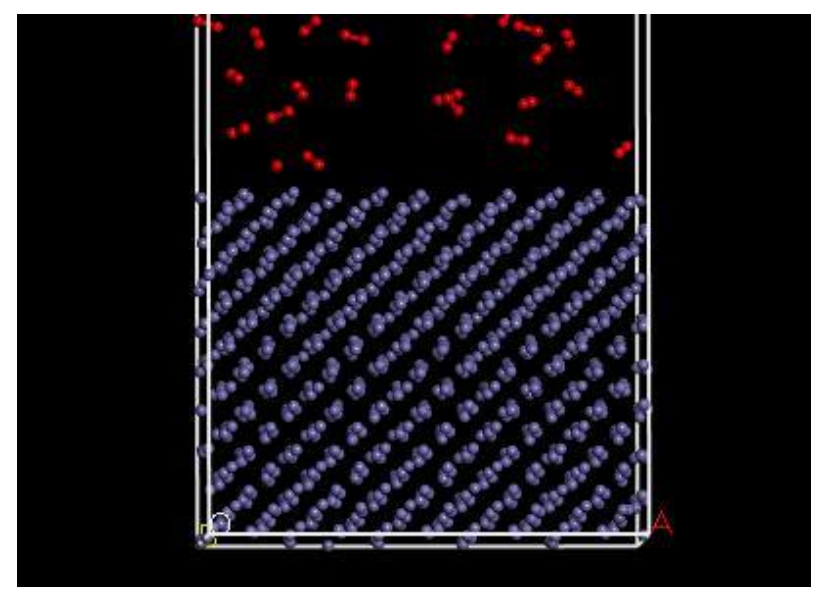

a

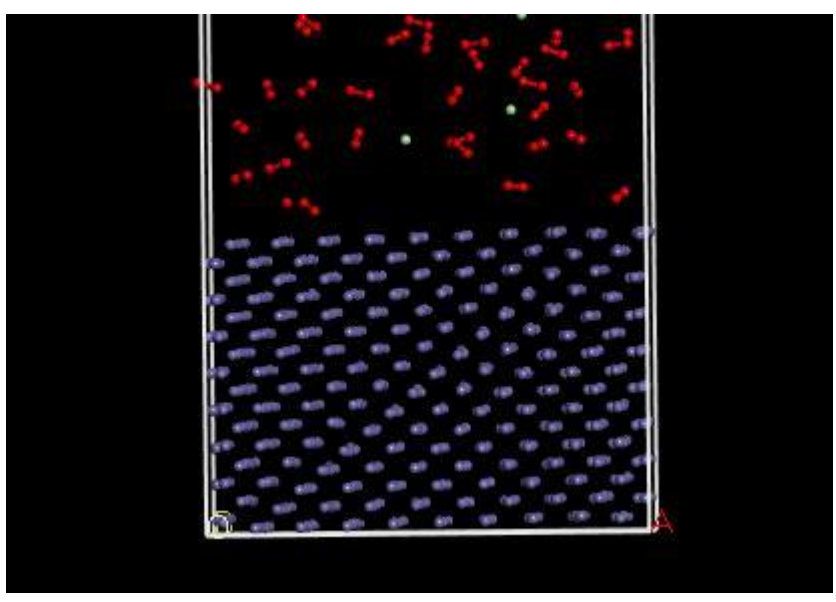

b

Fig. 8. Model construction process of iron oxidation reaction: $\mathrm{a}$ - without chloride ion; $\mathrm{b}$ - with chloride ion

\subsection{Results and discussion}

Fig. 9 shows the snapshots of the configuration of $\mathrm{Fe}$ oxidation reaction, which is based on the models constructed in Table 1. The oxidation depths calculated for five individual systems are shown in Table 2. As is shown by the results obtained from model L0, a thin oxidation layer is formed on the surface of the Fe substrate, which indicates that the oxidation reaction can occur without the present of chlorides. The calculated oxidation depth is about $2.21 \AA$. However, under the attack of chloride ions, the oxidation depth of model $\mathrm{LO}-\mathrm{Cl}$ is about $4.08 \AA$. Compared to model L0, it has an $85 \%$ increase, which is very substantial. While under the combined action of chloride attack and mechanical loading, the oxidation depth is found to increase obviously with the increased mechanical loading. When the applied strain is 0.2 , the oxidation depth is $10.88 \AA$. This, when compared to model $\mathrm{L} 0-\mathrm{Cl}$, has an increase of $6.80 \AA$. Therefore, the combined action of chloride attack and mechanical loading has a significant influence on the oxidation process of reinforcement. This is attributed to the change of bond energy between atoms. The uniaxial tension leads an increase in the distance between Fe atoms, which reduces the ionic bonding between $\mathrm{Fe}$ atoms, and thus makes Fe atoms easier to combine with oxygen atoms. On the other hand, chloride ions can increase the adsorption energy of $\mathrm{Fe}-\mathrm{O}$, which facilitates the bonding between $\mathrm{Fe}$ and oxygen atoms. In summary, the combined action of chloride attack and mechanical loading can make the $\mathrm{Fe}$ matrix absorb more $\mathrm{O}_{2}$ atoms and with the increased applied loading the oxidation depth increases, which promotes the oxidation reaction of $\mathrm{Fe}$ matrix. When there is sufficient oxygen, a thicker corrosion layer can be formed on the surface of reinforcement.

Table 2. The calculated oxidation depth

\begin{tabular}{|c|c|c|c|c|c|}
\hline Model code & L0 & L0-Cl & L5-Cl & L10-Cl & L20-Cl \\
\hline Depth, $\AA$ & 2.21 & 4.08 & 5.28 & 6.08 & 10.88 \\
\hline
\end{tabular}

Mean square displacement (MSD) is a method to determine the displacement patterns of particles over time, which can help determine whether particles are free to spread and transport. In molecular dynamics simulation, MSD can be obtained directly from the particle position, as shown in Eq. 1.

$$
\begin{aligned}
& M S D=\frac{1}{T-\Delta t} \int_{0}^{T-\Delta t}[r(t-\Delta t)-r(t)]^{2} d t . \\
& =\left\langle[r(t-\Delta t)-r(t)]^{2}\right\rangle
\end{aligned}
$$

where $T$ is the total simulation time, $r(\mathrm{t})$ is the location of atoms at the time of $t$.

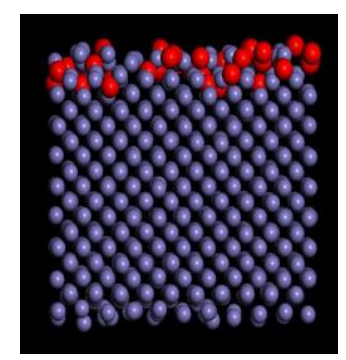

a

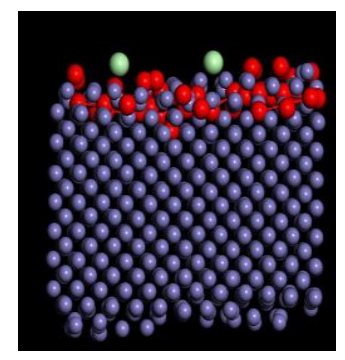

b

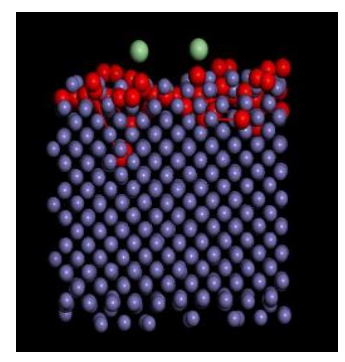

c

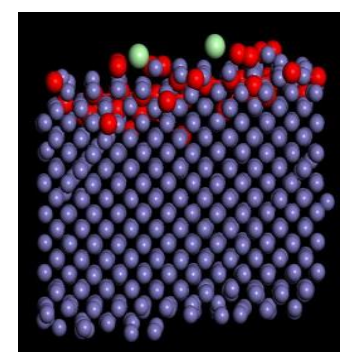

d

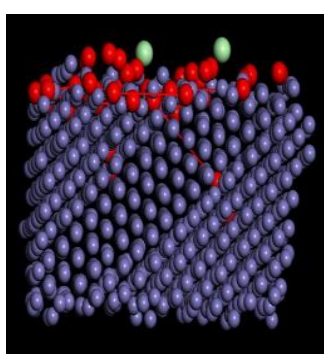

e

Fig. 9. Snapshots of the configuration of Fe oxidation reaction: $\mathrm{a}-\mathrm{L} 0 ; \mathrm{b}-\mathrm{L} 0-\mathrm{Cl} ; \mathrm{c}-\mathrm{L} 5-\mathrm{Cl} ; \mathrm{d}-\mathrm{L} 10-\mathrm{Cl} ; \mathrm{e}-\mathrm{L} 20-\mathrm{Cl}$ 
The MSD evolution of $\mathrm{O}_{2}$ under different conditions is shown in Fig. 10.

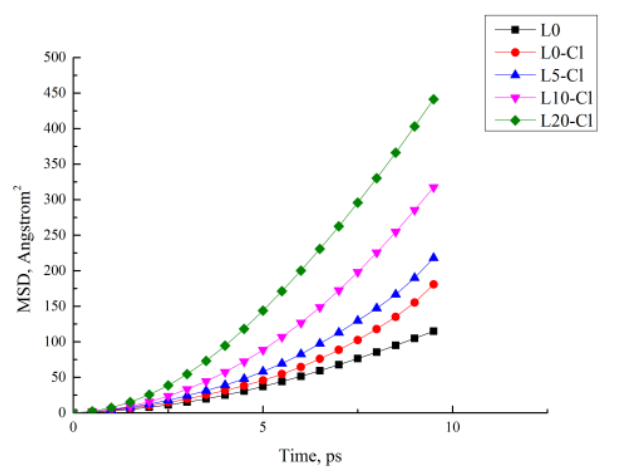

Fig. 10. The MSD evolution of $\mathrm{O}_{2}$ under different conditions

According to Einstein's law of diffusion, the calculation method of self-diffusion coefficient in MD simulation is obtained as shown in Eq. 2.

$D=\frac{1}{6} \lim _{\Delta t \rightarrow \infty} \frac{d M S D}{d \Delta t}$.

By linearly fitting the data in Fig. 10, the self-diffusion coefficient of $\mathrm{O}_{2}$ under different conditions is obtained as shown in Fig. 11.

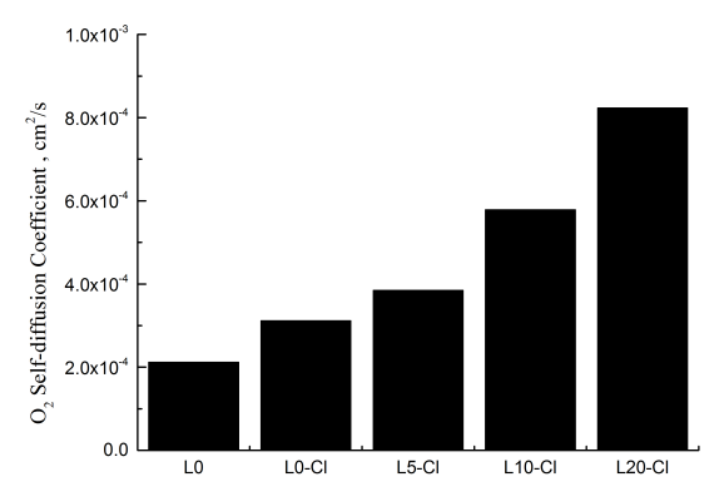

Fig. 11. The self-diffusion coefficient of $\mathrm{O}_{2}$ under different conditions

It can be seen from Fig. 10 that the existence of chloride can increase the MSD of $\mathrm{O}_{2}$. With the increase of static loading, the MSD of $\mathrm{O}_{2}$ gradually increases.

It is indicated from Fig. 11 that, chloride can increase the self-diffusion coefficient of $\mathrm{O}_{2}$ by $47.7 \%$, from $2.12 \times 10^{-4}$ to $3.13 \times 10^{-4}$. Besides, static loading can also increase the self-diffusion coefficient of $\mathrm{O}_{2}$ by $163.3 \%$.

\section{CONCLUSIONS}

This paper presents an investigation of the corrosion process of reinforcement under the combined action of chloride attack and mechanical loading by using MD simulation. The evolution of passive film and the oxidation process of reinforcement are simulated using Materials Studio software and the corresponding reaction mechanism is discussed in detail. The results have demonstrated that the present of chloride ions in the water system makes the Fe atoms separate from $\mathrm{Fe}_{3} \mathrm{O}_{4}$ easier and quicker, which leads to the passive film around reinforcement to be gradually stripped by chloride ions until it disappears. The oxidation depth of Fe matrix is found to increase substantially. The applied mechanical loading further affects the evolution of $\mathrm{Fe}_{3} \mathrm{O}_{4}$ structure, leading to the cracking of passive film. Owing to the combined action of chloride attack and static loading, the damage of passive film on the surface of reinforcement is aggravated. Especially when the applied strain reaches 0.2 , these cracks coalesce rapidly and the maximum crack width of passive film reaches to about $3.566 \AA$. The oxidation depth of $\mathrm{Fe}$ matrix is found to increase noticeably with the increased mechanical loading. The oxidation depth of $\mathrm{L} 20-\mathrm{Cl}$ reaches to about $10.88 \AA$, which is $167 \%$ of that of $\mathrm{LO}-\mathrm{Cl}$.

The existence of chloride increases the MSD and selfdiffusion coefficient of $\mathrm{O}_{2}$. Besides, the two parameters increases with static loading. It is indicated that the coupled effect of chloride and static loading accelerates the diffusion of $\mathrm{O}_{2}$ to the $\mathrm{Fe}$ matrix, and further increasing the oxidation reaction between the $\mathrm{Fe}$ matrix and $\mathrm{O}_{2}$.

\section{Acknowledgments}

The authors wish to acknowledge the financial support of "National Natural Science Foundation of China (Grant No. 51778577)" and "Natural Science Foundation of Ningbo (Grant No. 2018A610229)".

\section{REFERENCES}

1. Zhao, Y., Ding, H., Jin, W. Development of the CorrosionFilled Paste and Corrosion Layer at the Steel/Concrete Interface Corrosion Science 87 2014: pp. 199-210. https://doi.org/10.1016/j.corsci.2014.06.032

2. Xu, Y. The Corrosion Characteristics and Tensile Behavior of Reinforcement under Coupled Carbonation and Static Loading Materials 8(12) 2015: pp. 8561-8577. https://doi.org/10.3390/ma8125479

3. Ji, Y., Zhan, G., Tan, Z., Hu, Y., Gao, F. Process Control of Reinforcement Corrosion in Concrete. Part 1: Effect of Corrosion Products Construction and Building Materials 79 2015: pp. $214-222$. https://doi.org/10.1016/j.conbuildmat.2014.12.083

4. Ji, Y., Wu, M., Tan, Z., Gao, F., Liu, F. Process Control of Reinforcement Corrosion in Concrete. Part 2: TimeDependent Dominating Factors under Different Environmental Conditions Construction and Building Materials 73 2014: pp. 214-221. https://doi.org/10.1016/j.conbuildmat.2014.09.103

5. Stefanoni, M., Angst, U., Elsener, B. Local Electrochemistry of Reinforcement Steel - Distribution of Open Circuit and Pitting Potentials on Steels with Different Surface Condition Corrosion Science 98 2015: pp. $610-618$. https://doi.org/10.1016/j.corsci.2015.06.004

6. Sistonen, E., Cwirzen, A., Puttonen, J. Corrosion Mechanism of Hot-Dip Galvanised Reinforcement Bar in Cracked Concrete Corrosion Science 50 (12) 2008: pp. 3416-3428. https://doi.org/10.1016/j.corsci.2008.08.050

7. Chitty, W., Dillmann, P.L., Hostis, V., Lombard, C. LongTerm Corrosion Resistance of Metallic Reinforcements in Concrete-A Study of Corrosion Mechanisms based on 
Archaeological Artefacts Corrosion Science 47 (6) 2005: pp. $1555-1581$.

https://doi.org/10.1016/j.corsci.2004.07.032

8. Xu, Y., Qian, C. Influence of Coupled Chemomechanical Process on Corrosion Characteristics in Reinforcing Bars Journal of Wuhan University of Technology Materials Science Edition 28 (3) 2013: pp. 538-543. https://doi.org/10.1007/s11595-013-0727-0

9. Jaffer, S.J., Hansson, C.M. Chloride-Induced Corrosion Products of Steel in Cracked-Concrete Subjected to Different Loading Conditions Cement and Concrete Research 39 (2) 2009: pp. 116-125. https://doi.org/10.1016/j.cemconres.2008.11.001

10. François, R., Arliguie, G. Influence of Service Cracking on Reinforcement Steel Corrosion Journal of Materials in Civil Engineering 10 (1) 1998: pp. 14-20. https://doi.org/10.1061/(ASCE)0899-1561(1998)10:1(14)

11. Ballim, Y., Reid, J.C. Reinforcement Corrosion and the Deflection of RC Beams - An Experimental Critique of Current Test Methods Cement \& Concrete Composites 25 (6) 2003: pp. 625-632. https://doi.org/10.1016/S0958-9465(02)00076-8

12. Yu, L., François, R., Dang, V.H., Hostis, V., Gagné, R. Development of Chloride-Induced Corrosion in Pre-Cracked RC Beams under Sustained Loading: Effect of Load-Induced Cracks, Concrete Cover, and Exposure Conditions Cement and Concrete Research 67 2015: pp. 246-258. https://doi.org/10.1016/j.cemconres.2014.10.007

13. Jin, Z., Zhao, X., Zhao, T., Li, Y. Interaction between Compressive Load and Corrosive-Ion Attack on Reinforced Concrete with Accelerated Potentiostatic Corrosion Construction and Building Materials 113 2016: pp. $805-814$. https://doi.org/10.1016/j.conbuildmat.2016.03.115

14. Minoshima, Y., Seki, Y., Takayanagi, T., Motoyuki, S. Effects of Temperature and Isotopic Substitution on Electron Attachment Dynamics of Guanine-Cytosine Base Pair: RingPolymer and Classical Molecular Dynamics Simulations Chemical Physics 472 2016: pp. 1-8. https://doi.org/10.1016/j.chemphys.2016.02.019

15. Verners, O., Psofogiannakis, G., van Duin, A.C.T. Comparative Molecular Dynamics Study of Fcc-Al Hydrogen Embrittlement Corrosion Science 98 2015: pp. 40-49. https://doi.org/10.1016/j.corsci.2015.05.008
16. Li, L., Zhang, X., Gong, S., Zhao, H., Bai, Y., Li, Q., Ji, L. The Discussion of Descriptors for the QSAR Model and Molecular Dynamics Simulation of Benzimidazole Derivatives as Corrosion Inhibitors Corrosion Science 99 2015: pp. $76-88$. https://doi.org/10.1016/j.corsci.2015.06.003

17. Diamanti, M.V., Pérez Rosales, E.A., Raffaini, G., Ganazzoli, F., Brenna, A., Pedeferri, M., Ormellese, M. Molecular Modelling and Electrochemical Evaluation of Organic Inhibitors in Concrete Corrosion Science 100 2015: pp. $231-241$. https://doi.org/10.1016/j.corsci.2015.07.034

18. Hou, D., Li, Z., Zhao, T., Zhang, P. Water Transport in the Nano-Pore of the Calcium Silicate Phase: Reactivity, Structure and Dynamics Physical Chemistry Chemical Physics 17 (2) 2015: pp. 1411-1423. http://dx.doi.org/10.1039/C4CP04137B

19. Yao, H., Dai, Q., You, Z. Chemo-Physical Analysis and Molecular Dynamics (MD) Simulation of Moisture Susceptibility of Nano Hydrated Lime Modified Asphalt Mixtures Construction and Building Materials 101 2015: pp. 536-547. https://doi.org/10.1016/j.conbuildmat.2015.10.087

20. Rai, B. Molecular modeling for the design of novel performance chemicals and materials. CRC Press, Florida, 2012: pp. $1-26$.

21. van Duin, A.C.T., $\quad$ Dasgupta, S., Lorant, F., Goddard, W.A. Goddard, ReaxFF: A Reactive Force Field for Hydrocarbons The Journal of Physical Chemistry A 105 (41) 2001: pp. 9396-9409. https://doi.org/10.1021/jp004368u

22. Earnshaw, A., Greenwood, N. Chemistry of the Elements ( $2^{\text {nd }}$ edition). Elsevier Ltd, Oxford, 1997: pp 1070-1109.

23. Gunay, H.B., Ghods, P., Isgor, O.B., Carpenter, G., Wu, X. Characterization of Atomic Structure of Oxide Films on Carbon Steel in Simulated Concrete Pore Solutions using EELS Applied Surface Science 274 2013: pp. 195-202. https://doi.org/10.1016/j.apsusc.2013.03.014

24. Ashcroft, N.W., Mermin, N.D. Solid state physics. Cengage Learning, Boston, 1976: pp. 1-17.

25. Kittel, C., Holcomb, D.F. Introduction to Solid State Physics American Journal of Physics 35 (6) 1967: pp. 547-548. https://doi.org/10.1119/1.1974177

26. Lide, D.R. CRC handbook of chemistry and physics. CRC Press, Florida, 2004: pp. 9-21. 